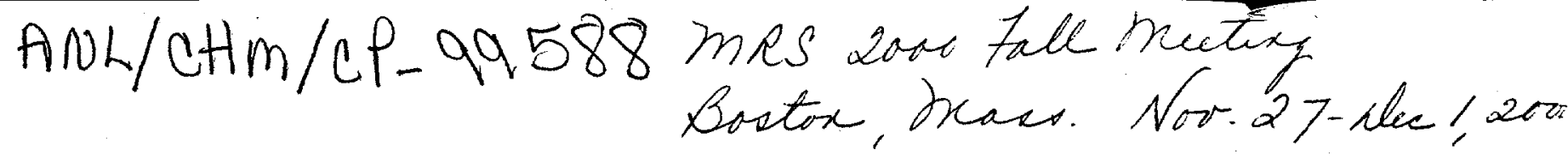

\title{
THE STRUCTURE OF ACTINIDE IONS EXCHANGED INTO NATIVE AND MODIFIED ZEOLITES AND CLAYS
}

\section{STEPHEN R. WASSERMAN*, L. SODERHOLM**, DANIEL M. GIAQUINTA**}

*Advanced Photon Source, Argonne National Laboratory, 9700 S. Cass Ave., Argonne IL, 60439

**Chemistry Division, Argonne National Laboratory, 9700 S. Cass Ave., Argonne II 60439

\section{ABSTRACT}

X-ray absorption spectroscopy (XAS) has been used to investigate the structure and valence of thorium $\left(\mathrm{Th}^{4+}\right)$ and uranyl $\left(\mathrm{UO}_{2}{ }^{2+}\right)$ cations exchanged into two classes of microporous aluminosilicate minerals: zeolites and smectite clays. XAS is also employed to examine the fate of the exchanged cations after modification of the mineral surface using self-assembled organic films and/or exposure to hydrothermal conditions. These treatments serve as models for the forces that ultimately determine the chemical fate of the actinide cations in the environment. The speciation of the cations depends on the pore size of the aluminosilicate, which is fixed for the zeolites and variable for the smectites.

\section{INTRODUCTION}

Recent studies have examined the effect of organic surface modification and hydrothermal treatments on the structure of various ions, including uranium, iron, and thorium, that had been exchanged into the interlayer of natural clay minerals. ${ }^{1-4}$ The surface modification involved the addition of a thin hydrophobic organic film derived from either octadecyltrimethoxy- or octadecyltrichlorosilane, $\mathrm{CH}_{3}\left(\mathrm{CH}_{2}\right){ }_{17} \mathrm{SiX}_{3}, \mathrm{X}=-\mathrm{OCH}_{3}$, $-\mathrm{Cl}$. These studies demonstrated that reduction and aggregation of the interlayer ions can occur upon hydrothermal treatment of the modified clays. The reactions of the interior metal cations generally follow the reduction potential of the ion and its susceptibility to hydrolysis in aqueous solution. In this paper we extend these experiments to thorium ( $\mathrm{Th}^{4+}$ ) and uranyl $\left(\mathrm{UO}_{2}{ }^{2+}\right)$ exchanged into zeolites.

The structures of the zeolites used for these experiments are shown in Figure 1, together with that of the smectite clay used in previous experiments. Both the zeolites and
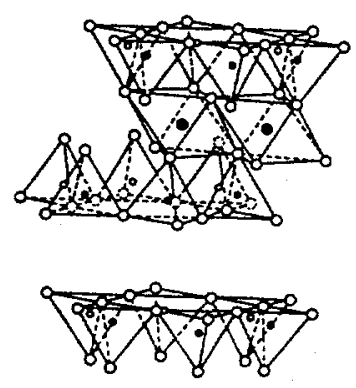

Smectite Clay

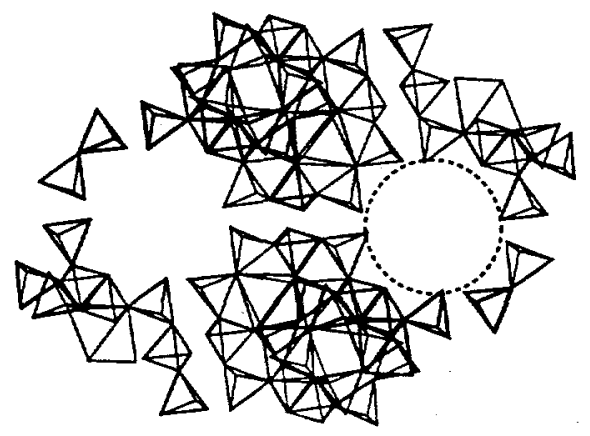

Faujasite

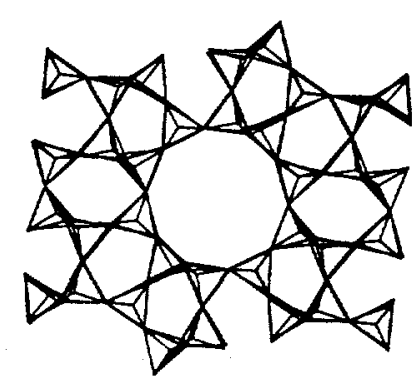

ZSM-5

Figure 1. Structures of a smectite clay and two types of zeolites: faujasite and ZSM-5. The pore sizes of the zeolites are 7.4 and 5.1-5.6 $\AA$, respectively.

The submitted manuscript has been created by the University of Chicago as Operator of Argonne National Laboratory ("Argonne") under Contract No. W-31-109-ENG-38 with the U.S. Department of Energy. The U.S. Government retains for itself, and others acting on its behalt, a paid-up, nonexclusive, irrevocable worldwide license in said article to reproduce, prepare derivative works, distribute copies to the public, and perform publicly and display publicly, by or on behalt of the Government. 


\section{DISCLAIMER}

This report was prepared as an account of work sponsored by an agency of the United States Government. Neither the United States Government nor any agency thereof, nor any of their employees, make any warranty, express or implied, or assumes any legal liability or responsibility for the accuracy, completeness, or usefulness of any information, apparatus, product, or process disclosed, or represents that its use would not infringe privately owned rights. Reference herein to any specific commercial product, process, or service by trade name, trademark, manufacturer, or otherwise does not necessarily constitute or imply its endorsement, recommendation, or favoring by the United States Government or any agency thereof. The views and opinions of authors expressed herein do not necessarily state or reflect those of the United States Government or any agency thereof. 


\section{DISCLAIMER}

Portions of this document may be illegible in electronic image products. Images are produced from the best available original document. 
clays are aluminosilicates. Substitutions within the framework result in a net negative charge for the aluminosilicate. In both zeolites and smectite clays, aluminum replaces silicon, while in the clays additional substitutions of magnesium for aluminum occur. Electrical neutrality in both classes of materials is maintained through the presence of cations, either within the interlayer of the clay or inside the pores of the zeolites. The cations in the native materials can be exchanged for other ions, such as the $\mathrm{Th}^{4+}$ and $\mathrm{UO}_{2}{ }^{2+}$ used in these experiments. For the zeolites, the cation exchange capacity is proportional to the incorporation of aluminum into the framework. In this study two types of zeolites were used. The first, faujasite, has a symmetrical pore structure with a diameter of $7.4 \AA$. The second, ZSM-5, has a slightly smaller pore, whose diameter varies between 5.1 and $5.6 \AA$. The fixed sizes of the openings into the interior of the zeolite contrast with the variable interlayer dimensions of the smectite, which depends on the degree of hydration of the clay.

\section{EXPERIMENTAL SECTION}

The preparation of ion-exchanged and surface-modified zeolites followed the same procedures previously used for the creation of the corresponding clay minerals. $1-4$ Hydrothermal treatments also mirrored the earlier procedures and exposed the zeolites to water at $200^{\circ} \mathrm{C}$ within a Teflon bomb. X-ray absorption spectra for uranyl and thorium in faujasite were obtained at the Advanced Photon Source (APS) using BESSRC beamline 12BM. Beamline 4-3 of the Stanford Synchrotron Radiation Laboratory (SSRL) was used

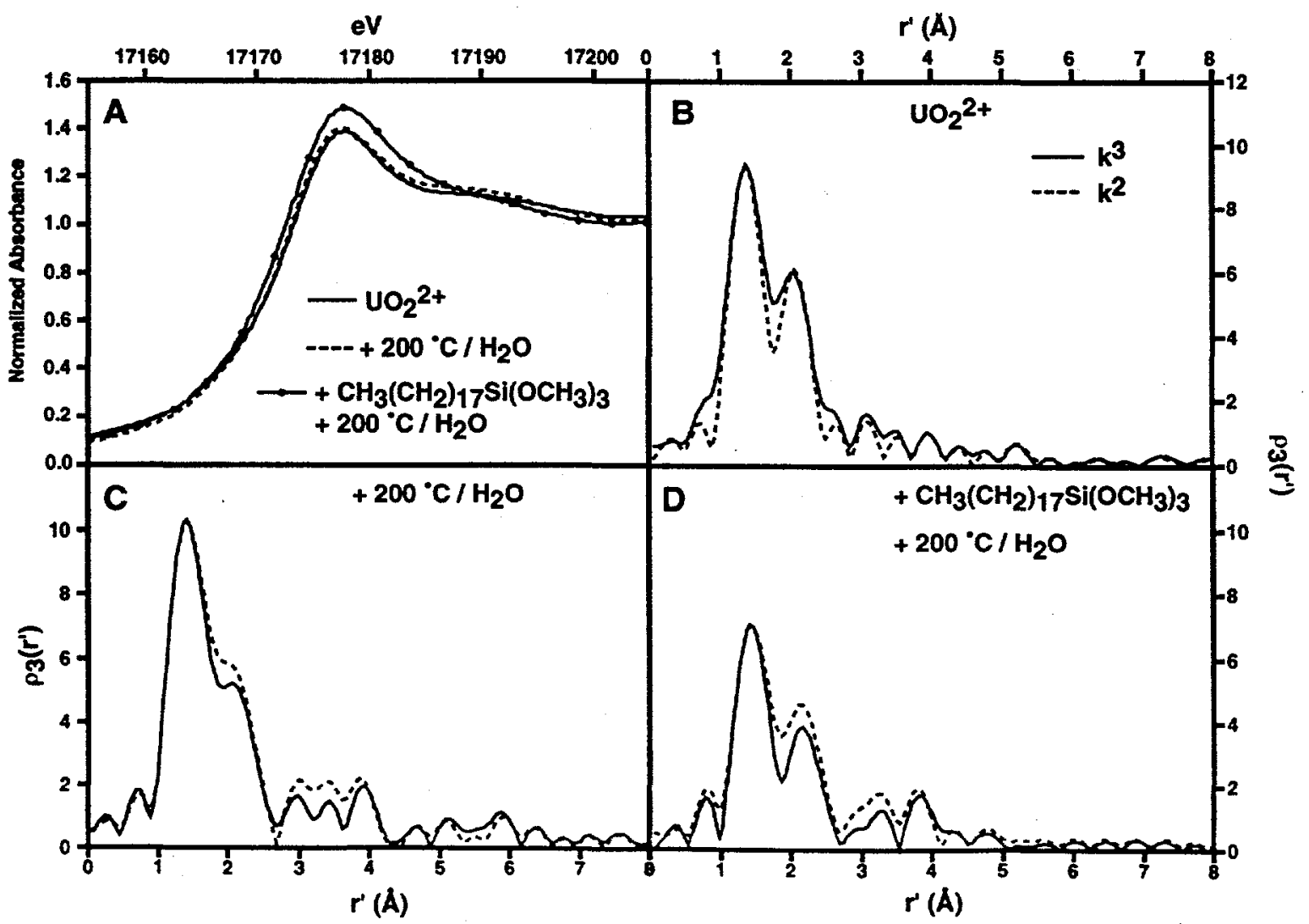

Figure 2. X-ray absorption near edge spectra (XANES) (A) and radial structure functions ( $B-D$, not phase corrected) for uranyl in faujasite. The radial structure functions for each of the three samples shown in $A$ are presented separately in $B, C$, and D. (1) ion-exchanged zeolite $(A-, B),(2)$ after hydrothermal processing at $200{ }^{\circ} \mathrm{C}(\mathrm{A}-\cdots, \mathrm{C})$ and $(3)$ following formation of a monolayer from octadecyltrimethoxysilane, $\mathrm{C}_{18} \mathrm{H}_{37} \mathrm{Si}\left(\mathrm{OCH}_{3}\right)_{3}$, and hydrothermal treatment $(\mathrm{A}-\mathrm{C}-\mathrm{D})$. For each radial structure function, transforms of the $\mathrm{k}^{3} \chi(\mathrm{k})(-)$ and $\mathrm{k}^{2} \chi(\mathrm{k})(-\cdot \cdot)$ data are presented. The range for the forward Fourier transforms was $\Delta \mathrm{k}=2.5-$ $10.5 \AA-1$ 
for the samples that incorporated uranyl into ZSM-5. The monochromators at each station were equipped with $\mathrm{Si}<111>$ and $\mathrm{Si}<220>$ crystals, respectively. Data for the uranylexchanged ZSM-5 were collected in fluorescence mode using a Lytle detector whose ion chamber contained krypton gas. A 9-element germanium detector measured the fluorescence from the faujasite samples that contained thorium or uranyl. A 3-absorption-length strontium filter was placed between the sample and the ion chamber for the uranium L3-edge spectra. No filter was used during the collection of the thorium L3-edge spectra. At SSRL energy calibration was maintained through acquisition of the near-edge spectrum of $\mathrm{UO}_{2}$ before or after each spectrum. The experimental data were analyzed with XAMath, a package for XAS analysis based on Mathematica ${ }^{\circledR}$.5

\section{RESULTS}

The near-edge $x$-ray absorption spectra (XANES) and radial structure functions for uranyl exchanged into faujasite are shown in Figure 2. The data from the original exchanged zeolite are similar to those of uranyl in solution, with two axial oxygen ligands at $1.77 \AA$ and 4 to 5 equatorial oxygen atoms at $2.41 \AA .6$ Following hydrothermal treatment, the

differences in the spectra are relatively minor, suggesting that the uranium remains in the +6

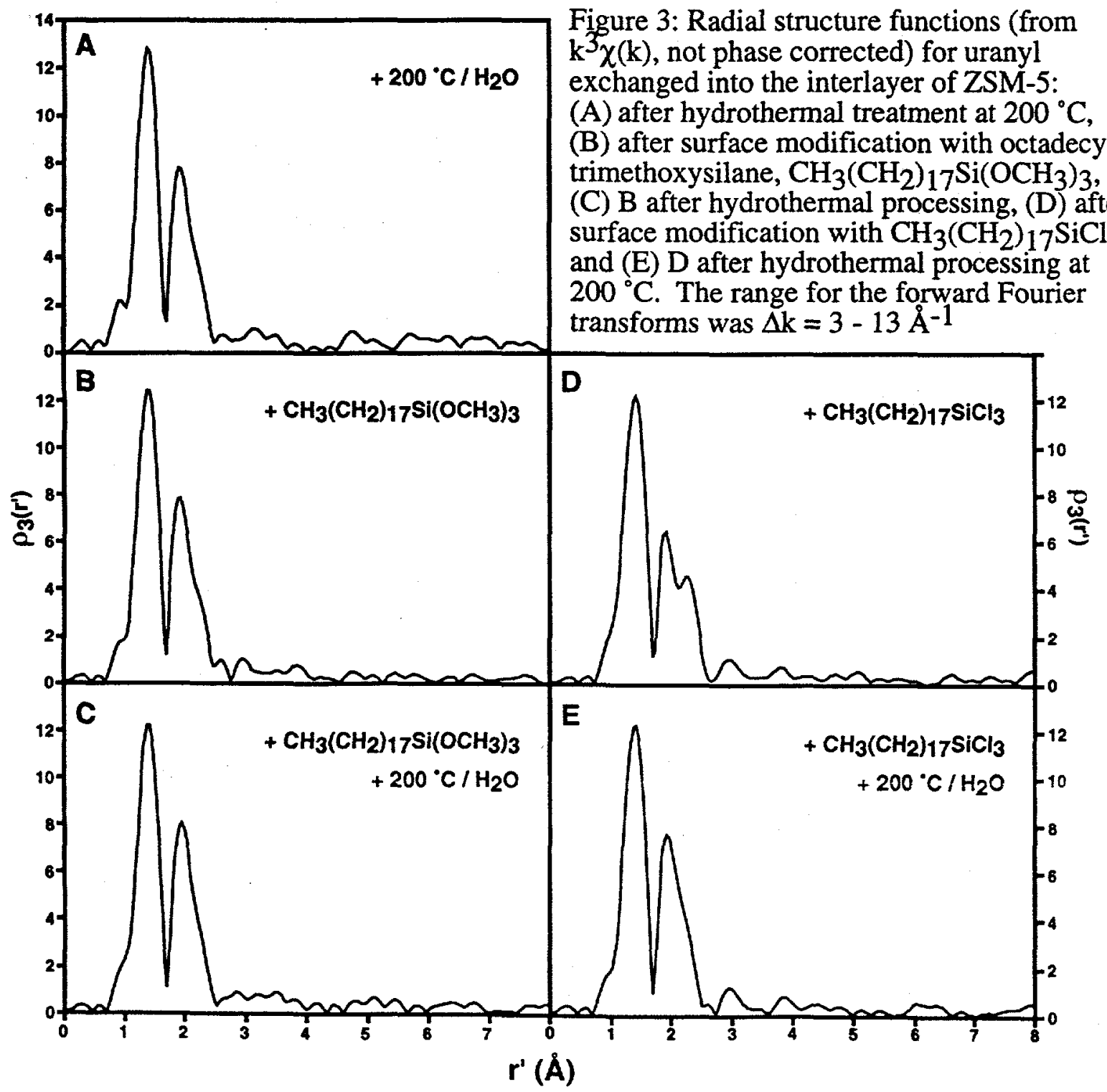


state, although the equatorial ligands appear somewhat more disordered. After coating the exchanged faujasite with a hydrophobic organic thin film generated using octadecyltrimethoxysilane followed by hydrothermal processing at $200^{\circ} \mathrm{C}$, the absorption edge of uranium shifts to lower energy by $0.7 \mathrm{eV}$ and the structure of the edge changes. In addition, the intensity of the feature in the radial distribution due to the axial ligands is reduced by approximately 25 percent. Since uranium is the only high- $Z$ element in this material, a comparison of the $\mathrm{k}^{2}$ - and $\mathrm{k}^{3}$-weighted EXAFS should indicate which, if any, of the features in the radial structure function are due to uranium-uranium interactions. No significantly greater intensity is found in the radial structure functions from any of the $\mathrm{k}^{3}$ EXAFS relative to the $\mathrm{k}^{2}$ data, thereby demonstrating that the uranium in these samples is isolated from the other uranium ions. These results are consistent with a partial reduction of the uranium in the zeolite to the +4 oxidation state upon addition of the organic coating and aqueous processing at elevated temperature. Similar reactivity has been observed for uranyl in smectite clays. 1,3 In the clay, however, a greater fraction of the uranyl is reduced and aggregation of the uranium into small $\mathrm{UO}_{2}$ clusters is also observed.

Figure 3 compares the radial structure functions of uranyl exchanged into a ZSM-5

Figure 4: Near-edge spectra and radial structure functions (without phase correction) for thorium(IV) exchanged into faujasite: (1) ion-exchanged zeolite, $(\mathrm{A}-, \mathrm{B})(2)$ after

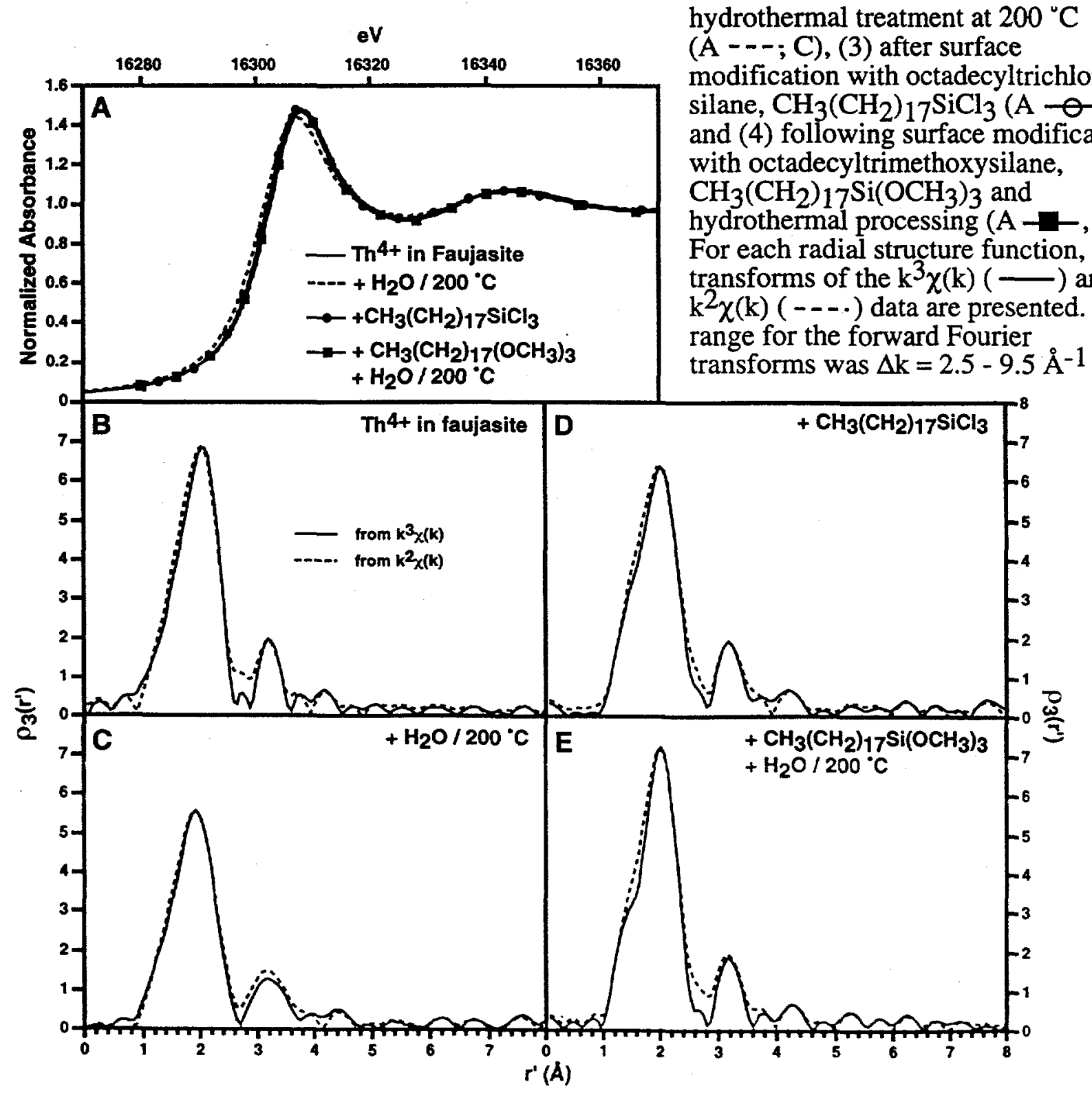


zeolite that contained 2.2 percent aluminum by weight. As found with the uranyl within faujasite, the uranyl structure remains intact after hydrothermal processing of the original exchanged zeolite. This structure is also preserved after addition of octadecyltrimethoxysilane to the exterior of the zeolite particles. In contrast to faujasite and the earlier observations for uranyl in clay, hydrothermal treatment of the hydrophobic material does not lead to reduction of uranyl to uranium(IV). However, when octadecyltrichlorosilane is used to modify the surface of the zeolite, chloride is found at the equatorial position of the uranyl. This ligand replaces approximately half of the oxygen at the equatorial position. The chloride anion is a by-product of the reaction between the silane and water or hydroxyl groups at the surface of the zeolite. After hydrothermal treatment of this sample, no chloride is found on the uranium within the zeolite. Identical results were obtained from corresponding samples created using a second ZSM-5 zeolite whose aluminum content was 1.7 percent.

The results of similar measurements on thorium(IV) exchanged into faujasite are presented in Figure 4. Both the XANES and EXAFS data indicate that, after addition of a coating using the trimethoxysilane followed by hydrothermal treatment, the structure of the internal thorium is unperturbed. In contrast to the observations with uranyl in the same zeolite, the addition of a film based on the trichlorosilane does not result in a change in the shape or position of the edge, nor is chlorine detected in the coordination sphere of the thorium. However, upon hydrothermal processing of the thorium-exchanged zeolite, a shift in the edge of $0.7 \mathrm{eV}$ to lower energy occurs. A decrease in the observed intensity of the first coordination shell and a broadening of a second peak in the radial distribution function at $r^{\prime}=3.2 \AA$ is also observed. Based on a comparison of the Fourier transforms of $k^{2} \chi(k)$ and $\mathrm{k}^{3} \chi(\mathrm{k})$, we conclude that the latter feature is probably due to an interaction with the surface of the zeolite and does not reflect aggregation of the thorium. These results may indicate that some hydrolysis of the thorium has occurred.

Attempts to introduce thorium into the ZSM-5 apparently failed. While it is difficult to assess accurately the concentration of an element within a powder sample based on a comparison of edge jumps, we estimate that the thorium content of the exchanged ZSM-5 is less than 5 percent of the corresponding sample created using faujasite. This low concentration precluded the use of XAS to determine the speciation of the thorium that was present. The successful introduction of $\mathrm{Th}^{4+}$ into faujasite and our inability to incorporate the ion into ZSM-5 suggests that the cross-sectional size of an aqueous thorium complex is at least that of the pore size of the ZSM-5 but less than that of faujasite.

\section{DISCUSSION}

Our results demonstrate that the geometrical structure of zeolites and clays plays a significant role in the reactions of uranyl and thorium(IV) within exchanged and modified aluminosilicates. Within the variable pores of smectite clays, reduction of uranyl occurs readily. The small pores of the zeolites, fixed in size, limit the interactions that lead to changes in oxidation state and prevent subsequent aggregation. For thorium in faujasite, even if hydrolysis of the cation has occurred to some degree, the restricted motion of the cation prevents any coalescence of the actinide species. The differences in reactivity reflect changes in the mobility of the ions, and possibly the reducing agent, within the pores, which results in an entropic difference in the reaction free energy.

The experiments reported here raise two additional issues regarding the properties of uranyl and thorium(IV) within the exchanged and modified zeolites. First, why does the chloride coordinated to the uranyl within ZSM-5 after addition of the trichlorosilane disappear during hydrothermal processing? It is possible that this disappearance reflects loss of uranium from the sample, rather than alteration of the coordination of the actinide ion. In earlier work we demonstrated that, when octadecyltrichlorosilane is used to modify a smectite clay, the uranium can leach from the sample. ${ }^{1}$ However, when the coating on the clay is created from the corresponding trimethoxysilane, the uranium remains within the 
interlayer. For the clays and zeolites, the cations are held within the pores or interlayer by coulombic forces. The replacement of at least two neutral equatorial water molecules by chloride anions results in a neutral or negatively charged complex that can escape, in the presence of bulk water, into solution. Our inability to detect any chloride after hydrothermal treatment can be used to develop hypotheses concerning the presence of mixed aquo-chloro species in these systems.

The second issue in these studies on cation interactions within modified microporous solids is whether the exchanged ions are located in the interior of the aluminosilicate particle or merely adsorbed on the external surface. Our results suggest that the former is the best description for these organic-inorganic composites. The fact that only minor amounts of thorium are found in the ZSM-5 compared to faujasite indicates that pore size affects incorporation, which in turn suggests that the cation passes into the core of the zeolite. The observed differences in the speciation of uranyl within zeolites and clays, after modification of the aluminosilicate surface and hydrothermal treatment, also imply that the cation is in the interior of the aluminosilicate.

\section{CONCLUSION}

The results described here demonstrate the variety of reactions that can occur between actinide metals and water and organic materials within microporous aluminosilicates. These extensions of our earlier studies with clays show that the reactivity of actinide cations depends strongly on the structure, and not just the composition, of the mineral interface. The results are suggestive of the complexity of actinide speciation in the environment.

\section{ACKNOWLEDGMENTS}

We would like to thank Steven E. Yuchs for aid in the preparation of these samples and S. Skanthakumar for assistance during the acquisition of the XAS data. This work was supported by the U. S. Department of Energy, Office of Basic Energy Sciences-Chemical Sciences (L. S., and D. G.) and Materials Sciences (S. R. W.) under contract W31-109-ENG38.

\section{REFERENCES}

1. Stephen R. Wasserman, Daniel M. Giaquinta, Steven E. Yuchs, and L. Soderholm, in Scientific Basis for Nuclear Waste Management, edited by W. J. Gray and Ines R. Triay (Mater. Res. Soc. Proc. 465, Pittsburgh, PA, 1997) pp. 473-480.

2. Stephen R. Wasserman, L. Soderholm, and Urs Staub, Chem. Mater., 10, 559-566 (1998)

3. D. M. Giaquinta, L. Soderholm, S. E. Yuchs, S. R. Wasserman, Radiochim. Acta, 76, 113-121 (1997).

4. D. M Giaquinta, L. Soderholm, S. E. Yuchs, and S. R. Wasserman, J. Alloys Compounds, $249,142-145$ (1997)

5. S. R. Wasserman. XAMath is available on the World Wide Web at ixs.csrri.iit.edu/ database/programs/XAMath.

6. P. G. Allen, J. J. Bucher, D. K. Shuh, N. M. Edelstein, and T. Reich,. Inorg. Chem., 36, 4676-4683 (1997) 